\title{
CRESCIMENTO VEGETATIVO INICIAL DE ABACAXIZEIRO EM FUNÇÃO DA CULTURA DE COBERTURA E APLICAÇÃO DE GESSO
}

\author{
Wanderson Mendes Martins ${ }^{1}$, Leonarda Grillo Neves ${ }^{1}$, Milson Evaldo Serafim ${ }^{2}$, Kelly Lana \\ Araújo $^{1}$, Walmes Marques Zeviani ${ }^{3}$, Nadsley Seraglio Souza ${ }^{1}$ \\ ${ }^{1}$ Universidade do Estado de Mato Grosso (UNEMAT), Departamento de Agronomia, Campus Cáceres, E-mail: \\ wandersonc3_hand@hotmail.com, leonardaneves@unemat.br, kellylana_araujo@yahoo.com.br, nadsley_seraglio@hotmail.com \\ ${ }^{2}$ Instituto Federal de Educação, Ciência e Tecnologia de Mato Grosso (IFMT), Campus Cáceres, E-mail: \\ milson.serafim@cas.ifmt.edu.br \\ ${ }^{3}$ Universidade Federal do Paraná - UFPR, E-mail: walmes@ufpr.br
}

\section{RESUMO}

O objetivo deste trabalho foi avaliar o crescimento vegetativo inicial de quatro cultivares de abacaxizeiro ('Smooth Cayenne', 'Imperial', 'IAC Fantástico' e 'Pérola') em resposta à cultura de cobertura e à aplicação de gesso agrícola no solo. Nas condições edafoclimáticas da região de Cáceres - MT a cultivar 'Pérola' apresentou maior crescimento vegetativo inicial, se destacando em relação às cultivares 'Smooth Cayenne', 'Imperial' e 'IAC- Fantástico'. O emprego da cultura de cobertura favoreceu o crescimento vegetativo inicial das cultivares de abacaxizeiro, porém não foi observado efeito significativo da aplicação de gesso nas taxas de crescimento em altura das plantas, crescimento em diâmetro da roseta e crescimento em diâmetro do caule.

Palavras-chave: Ananas comosus, gesso, sistemas de manejo

\section{INITIAL VEGETATIVE GROWTH OF PINEAPPLE IN FUNCTION OF CROP COVER AND GYPSUM APPLICATION}

\begin{abstract}
The objective of this study was to evaluate the initial vegetative growth of four pineapple cultivars ('Smooth Cayenne', 'Imperial', 'IAC Fantastic' and 'Pearl') in response to cover crop and application of agricultural gypsum to the soil. In the environmental conditions of the region of Cáceres - MT, State of Mato Grosso, Brazil, the cultivar 'Pearl' showed initial vegetative growth higher, than that of the cultivars 'Smooth Cayenne', 'Imperial' and 'Fantastic IAC-'. The cover crops favored the initial vegetative growth of the pineapple cultivars, however one observed no significant effect of gypsum application in the growth rates in height of the plants, rosette diameter and stem diameter.
\end{abstract}

Keywords: Ananas comosus, gypsum, management systems 


\section{INTRODUÇÃO}

O Brasil se destaca no cenário mundial como um dos principais produtores de abacaxi [Ananas comosus L. Merril] (FAO, 2014). Na safra de 2011, a produção brasileira de abacaxi foi de aproximadamente 2,3 milhões de toneladas, representando cerca de $11 \%$ da produção mundial. No Estado de Mato Grosso a produtividade média é de 21,87 frutos por hectare, estando abaixo da média nacional $\left(25,24\right.$ frutos.ha $\left.{ }^{-1}\right)$. O estado do Pará, com 30,17 frutos.ha ${ }^{-1}$, possui a melhor produtividade brasileira de abacaxi (IBGE, 2014).

No Brasil, o abacaxizeiro é explorado há muitas décadas, de forma predominante, em pequenas propriedades, com áreas médias inferiores a cinco hectares, onde se emprega na maioria das vezes a mão de obra familiar, com recursos próprios para implantação e manutenção da lavoura. Nos últimos anos, o agronegócio do abacaxi tem crescido muito, transformando-se no principal sustentáculo econômico de várias regiões em que a espécie é cultivada (CUNHA, 2007).

A cultura de cobertura é uma técnica que consiste no cultivo de uma cultura intercalar à cultura principal com o objetivo de dar cobertura ao solo, seja pela sua massa verde, seja pelos resíduos produzidos após cada corte. O resíduo depositado no solo é capaz de trazer benefícios aos atributos físicos, químicos e biológicos do solo (SANTOS et al., 2011), além de reduzir a infestação de plantas daninhas (OLIVEIRA et al., 2008; SEDIYAMA et al., 2010) e a necessidade de irrigação (LIMA et al., 2009; CARVALHO et al., 2011). O gesso agrícola por sua vez, possibilita melhores condições químicas no perfil (CAIRES et al., 2004; RAIJ, 2008), diminuindo a saturação por alumínio e aumentando os teores de cálcio e enxofre (VITTI et al., 2008).

O estudo de adaptação regional de novas cultivares de abacaxi e de sistemas de manejo são fundamentais para impulsionar a cultura do abacaxi, tornando-se mais uma opção de renda para as pequenas propriedades. Neste sentido, objetivou-se, com este trabalho, avaliar o efeito da cultura de cobertura e do gesso agrícola no crescimento vegetativo inicial de quatro cultivares de abacaxizeiro no Município de Cáceres, MT.

\section{MATERIAL E MÉTODOS}

$\mathrm{O}$ experimento foi realizado na área experimental do Instituto Federal de Educação, Ciências e Tecnologia do Mato 
Grosso (IFMT), Campus Cáceres, localizada no Município de Cáceres-MT, cujas coordenadas médias são $16^{\circ} 7^{\prime} 50^{\prime \prime} \mathrm{S}$ e $57^{\circ} 41^{\prime} 41^{\prime \prime} \mathrm{O}$, e altitude de $120 \mathrm{~m}$.

O clima de Cáceres é tropical, tipo Aw segundo a classificação de Köppen, terceiro megatérmico, estação seca de maio a outubro e chuvas de novembro a abril, (NEVES et al., 2011). O solo da área experimental, segundo metodologia do Sistema Brasileiro de Classificação de Solos (EMBRAPA, 2006) é classificado como Latossolo Vermelho-Amarelo distrófico (LVA) e textura média.

$\mathrm{O}$ experimento foi conduzido em delineamento em blocos ao acaso, arranjados no esquema fatorial $4 \times 2 \times 2$, sendo quatro cultivares, dois níveis de cultura de cobertura e dois níveis de gesso agrícola, com quatro repetições. A unidade experimental foi formada por 20 plantas, totalizando 1.280 plantas no experimento. As cultivares avaliadas foram: 'Smooth Cayenne', 'Imperial', 'IAC Fantástico' e 'Pérola'. O plantio foi realizado no espaçamento de $0,90 \times 0,40 \times 0,40 \mathrm{~m}$. As mudas utilizadas no plantio foram do tipo filhotes com 20 a $40 \mathrm{~cm}$, de acordo com o padrão de cada cultivar. Os dois níveis de gesso agrícola no sulco de plantio foram: sem gesso e com aplicação de gesso agrícola na dose 4 t.ha ${ }^{-1}$, conforme Ribeiro et al. (1999), para uma correção esperada até 0,6 metros. Os níveis de cultura de cobertura foram com ou sem milheto (Pennisetum glaucum), plantado entre as fileiras duplas. As plantas de milheto foram manejadas (corte) sempre que atingiam 0,60 $\mathrm{m}$ de altura, sendo o material deixado sobre o solo.

$\mathrm{Na}$ análise do crescimento das plantas foram utilizadas as variáveis de altura da planta (AP), diâmetro da roseta (DR) e diâmetro do caule (DC). Essas medições foram realizadas aos 60 e 90 dias após o plantio das cultivares, em cinco plantas selecionadas ao acaso de cada parcela. A AP foi considerada como distância compreendida entre o colo da planta até o ápice foliar, sendo mensurada com auxílio de fita métrica. O DR foi considerado a maior distância linear entre o ápice de folhas opostas. Medidas do DC foram realizadas com auxílio de um paquímetro digital. Com base nos dados obtidos nas três avaliações de AP, DR e DC calcularam-se, respectivamente, a taxa de crescimento em altura das plantas (TCA, cm $\operatorname{dia}^{-1}$ ), a taxa de crescimento em diâmetro da roseta (TCR, mm.dia ${ }^{-1}$ ) e a taxa de crescimento em diâmetro do caule (TCC, mm.dia $\left.{ }^{-1}\right)$. 


\section{CRESCIMENTO VEGETATIVO INICIAL DE ABACAXIZEIRO EM FUNÇÃO DA CULTURA DE COBERTURA E APLICAÇÃO DE GESSO}

O cálculo da taxa de crescimento (TC) foi realizado de acordo com a equação:

$$
\mathrm{TC}=\frac{\mathrm{L} 2-\mathrm{L} 1}{\mathrm{t} 2-\mathrm{t} 1}
$$

Sendo L2-L1 a diferença entre os valores reais mensurados em duas avaliações consecutivas e t2-t1 o intervalo de tempo entre as duas avaliações consecutivas.

Os dados foram analisados conforme modelo estatístico para experimento fatorial, $4 \times 2 \times 2$ com quatro repetições, em blocos ao acaso. O modelo foi ajustado e, em seguida, a análise dos resíduos foi feita para verificar o atendimento dos pressupostos. Em caso de fuga sistemática dos pressupostos, aplicou-se transformação de Box-Cox na variável resposta. A partir daí toda inferência se deu sobre a variável transformada. As médias foram representadas em gráficos com intervalo de confiança (95\%) associado para acessar a diferença entre tratamentos bem como a precisão das estimativas (CUMMING et al., 2007). Em todas as etapas da análise estatística adotou-se o nível nominal de significância de 5\%. Essas análises foram realizadas utilizando-se $\mathrm{o}$ aplicativo estatístico $\mathrm{R}$ DEVELOPMENT CORE TEAM (RDCT, 2012).

\section{RESULTADOS E DISCUSSÃO}

O resumo da análise de variância para a variável resposta taxa de crescimento em altura apresentou efeito significativo dos fatores cultivar e cultura de cobertura. Ocorreu também interação significativa para cultivar $\mathrm{x}$ cultura de cobertura, e gesso $\mathrm{x}$ cultura de cobertura. Para a variável diâmetro do caule foi observado efeito significativo para cultivar e para interação cultivar $\mathrm{x}$ gesso. $\mathrm{O}$ diâmetro da roseta apresentou efeito significativo somente para o fator cultivar (Tabela 1).

$\mathrm{Na}$ comparação entre cultivares, a maior taxa de crescimento em altura foi para a cultivar 'Pérola' (Figura 1). Nesta cultivar, os tratamentos com cultura de cobertura apresentaram taxa de crescimento significativamente maior que os tratamentos sem cobertura. $\mathrm{Na}$ cultivar 'Smooth Cayenne', 'IAC-Fantástico' e 'Pérola' foi observado efeito significativo da cultura de cobertura, sem gesso, em relação ao tratamento convencional (sem cobertura), demonstrando uma resposta destas cultivares a cobertura do solo. Para a cultivar 'Imperial' não foi observado efeito significativo dos tratamentos (Figura 1). 
Tabela 1. Resumo da análise de variância para plantas de abacaxizeiro sob os fatores de estudo cultivar, gesso e cobertura do solo, Cáceres, MT, 2011.

\begin{tabular}{lcccc}
\hline \multirow{2}{*}{ Fontes de Variação } & \multirow{2}{*}{ G.L. } & \multicolumn{3}{c}{ Quadrado Médio } \\
\cline { 3 - 5 } & 3 & $0,010468^{\mathrm{ns}}$ & $0,002634^{\mathrm{ns}}$ & $169,08^{\mathrm{ns}}$ \\
\hline Bloco & 3 & $0,063076^{*}$ & $0,152900^{*}$ & $1434,93^{*}$ \\
Cultivar & 1 & $0,002287^{\mathrm{ns}}$ & $0,001221^{\mathrm{ns}}$ & $169,65^{\mathrm{ns}}$ \\
Gesso & 1 & $0,051005^{*}$ & $0,008735^{\mathrm{ns}}$ & $141,78^{\mathrm{ns}}$ \\
Cobertura & 3 & $0,022835^{\mathrm{ns}}$ & $0,021028^{*}$ & $400,04^{\mathrm{ns}}$ \\
Cultivar: Gesso & 3 & $0,031102^{*}$ & $0,014907^{\mathrm{ns}}$ & $100,96^{\mathrm{ns}}$ \\
Cultivar: Cobertura & 1 & $0,042936^{*}$ & $0,013426^{\mathrm{ns}}$ & $306,15^{\mathrm{ns}}$ \\
Gesso: Cobertura & 3 & $0,007303^{\mathrm{ns}}$ & $0,002108^{\mathrm{ns}}$ & $93,89^{\mathrm{ns}}$ \\
Cultivar: Gesso: Cobertura & 301 & 0,009417 & 0,005868 & 154,54 \\
Resíduos & TCC & & &
\end{tabular}

$\mathrm{TCA}=$ taxa de crescimento em altura $\left(\mathrm{cmdia}^{-1}\right) ; \mathrm{TCC}=$ taxa de crescimento em diâmetro do caule $\left(\mathrm{mmdia}^{-1}\right) ; \mathrm{TCR}=$ taxa de crescimento do diâmetro da roseta $\left(\mathrm{mm} \cdot \mathrm{dia}^{-1}\right) ;{ }^{\text {ns }}$ - não significativo $\mathrm{e}^{*}$ significativo a $5 \%$ de probabilidade pelo teste F.

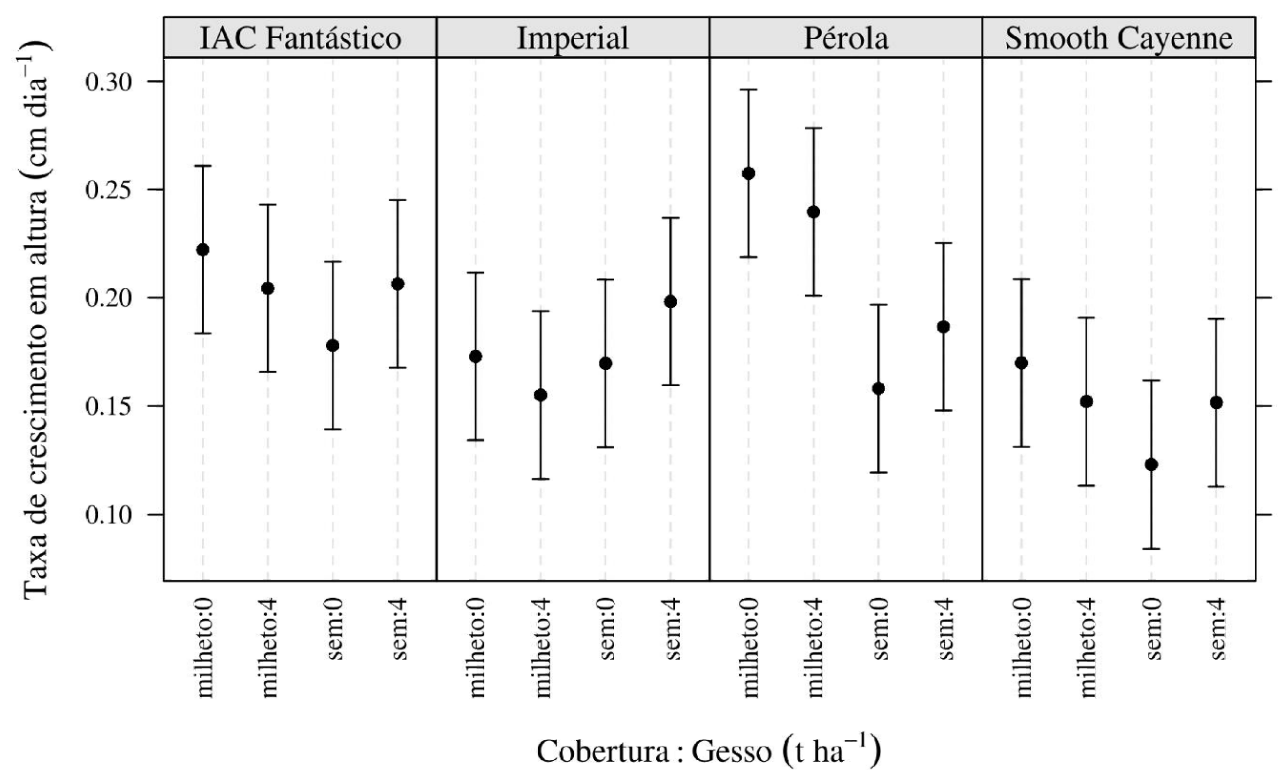

Figura 1. Estimativa intervalar para a taxa de crescimento em altura para as cultivares 'IACFantástico', 'Imperial', 'Pérola' e 'Smooth Cayenne' em função da cobertura do solo e da aplicação de gesso. Milheto: $0=$ Cobertura com milheto e sem aplicação de gesso; Milheto: 4 = Cobertura com milheto e com aplicação de gesso ( $\left.4 \mathrm{t} \mathrm{ha}^{-1}\right)$; Convencional: $0=$ Sem cobertura com milheto e sem aplicação de gesso; Convencional: 4 = Sem cobertura com milheto e com aplicação de gesso $\left(4 \mathrm{t} \mathrm{ha}^{-1}\right)$, Cáceres, MT, 2011. 


\section{CRESCIMENTO VEGETATIVO INICIAL DE ABACAXIZEIRO EM FUNÇÃO DA CULTURA DE COBERTURA E APLICAÇÃO DE GESSO}

$\mathrm{Na}$ comparação entre cultivares, a menor taxa de crescimento foi para a cultivar 'Smooth Cayenne' na condição convencional sem gesso. Esse tratamento foi significativamente menor em relação às demais cultivares na condição de cobertura sem gesso (Figura 1).

Para as quatro cultivares, na comparação dos tratamentos convencional com e sem gesso observa-se uma tendência numérica dos tratamentos com gesso superarem os tratamentos sem aplicação de gesso, indicando a capacidade do gesso em amenizar a ausência de cobertura do solo (Figura 2). Efeito contrário foi observado nos tratamentos com milheto, onde a presença do gesso reduziu a taxa de crescimento (Figura 2). Resultado de maior taxa de crescimento da cultivar 'Pérola' também foi observado em estudo com abacaxizeiro nas condições da Região da Mata Paraibana (RODRIGUÊS et al., 2010). O maior crescimento da cultivar 'Pérola' está de acordo com as proposições de Reinhardt et al. (2000), de que as plantas da cultivar 'Smooth Cayenne' são, em geral, de menor porte, podendo este raciocínio ser também aplicado às cultivares 'IAC Fantástico' e 'Imperial'. Este porte reduzido constitui em vantagem comparativa quando se refere às práticas de manejo.
O mercado interno de abacaxi no Brasil dá preferência para frutos graúdos e, nesse sentido, os aspectos que interferem no crescimento vegetativo das plantas no campo são determinantes para o sucesso econômico da atividade, pois há uma correlação positiva entre o tamanho da planta (peso de folha 'D') e o peso dos frutos (PY et al., 1984). Assim, o aumento significativo da taxa de crescimento das plantas, proporcionado pela cobertura do solo, é relevante na obtenção de frutos de maior tamanho.

Para a taxa de crescimento em diâmetro do caule não houve efeito significativo da cobertura. A cultivar 'Pérola' se destacou com uma taxa de crescimento em diâmetro do caule significativamente maior nos tratamentos sem gesso, quando comparada à condição com gesso na mesma cultivar, e às condições com e sem gesso das demais cultivares (Figura 2). $\mathrm{O}$ menor crescimento em diâmetro do caule foi para a cultivar 'IACFantástico', em que as condições com e sem gesso foram significativamente menores que as demais cultivares. Ainda na cultivar 'IAC-Fantástico' foi observada uma resposta positiva do DC a gesso (Figura 2).

Para a taxa de crescimento em diâmetro da roseta não se observou efeito significativo dos fatores cultura de cobertura 
e gesso. A cultivar 'Smooth Cayenne' apresentou uma taxa de crescimento em diâmetro da roseta significativamente maior que as demais cultivares. As cultivares
'IAC-Fantástico' e 'Pérola' foram significativamente maiores que a cultivar Imperial (Figura 3).

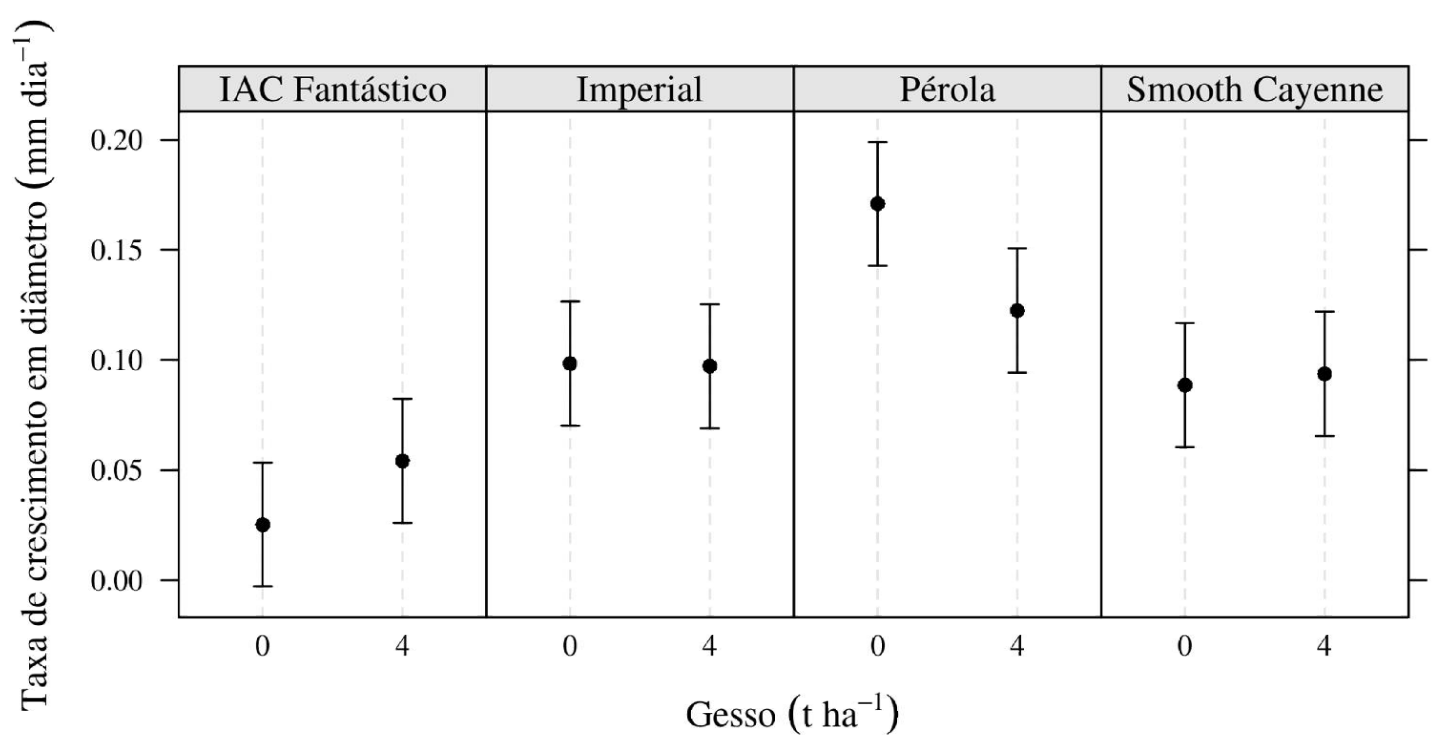

Figura 2. Estimativa intervalar para a taxa de crescimento em diâmetro para as cultivares 'IAC Fantástico', 'Imperial', 'Pérola' e 'Smooth Cayenne' em função da aplicação de gesso. $0=$ sem aplicação de gesso; $4=$ com aplicação de gesso $\left(4 \mathrm{t} \mathrm{ha}^{-1}\right)$, Cáceres, MT, 2011.

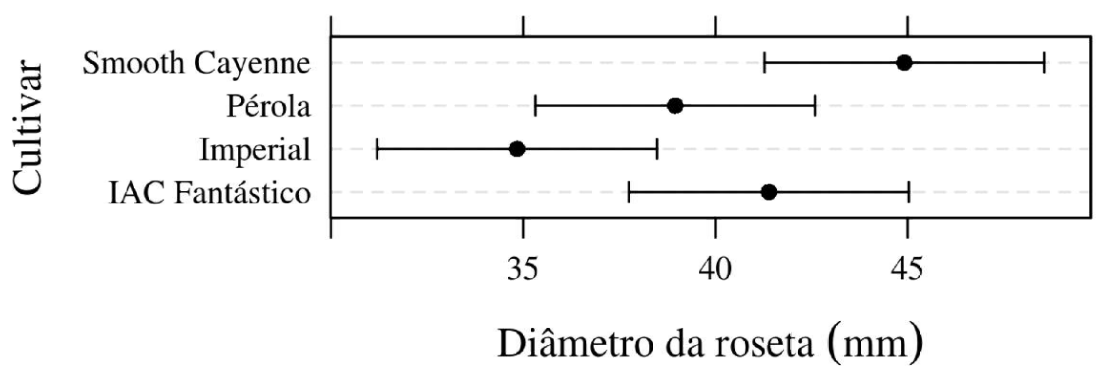

Figura 3. Estimativa intervalar para a taxa de crescimento em diâmetro da roseta para as cultivares 'IAC-Fantástico', 'Imperial', 'Pérola' e 'Smooth Cayenne', Cáceres, MT, 2011. 


\section{CONCLUSÕES}

A cultivar 'Pérola' apresenta maior taxa crescimento em altura, diâmetro e de caule quando comparada às cultivares 'Smooth Cayenne', 'Imperial' e 'IACFantástico'. Para taxa de crescimento em altura as cultivares 'Smooth Cayenne', 'IAC- Fantástico' e 'Pérola' respondem positivamente à cultura de cobertura, sem gesso. Nos tratamentos sem cobertura todas as cultivares apresentam resposta positiva de crescimento em altura com gesso. Nos tratamentos com cobertura não é observada resposta positiva ao gesso.

\section{REFERÊNCIAS BIBLIOGRÁFICAS}

CAIRES, E.F.; KUSMAN, M.T.; BARTH, G.; GARBUIO F. J.; PADILHA, J.M. 2004. Alterações químicas do solo e resposta do milho à calagem e aplicação de gesso. Revista Brasileira de Ciência do Solo, Viçosa, v. 28, n. 1, p. 125-136.

CARVALHO, J.F.; MONTENEGRO, A. A.A.; SOARES, T.M.; SILVA, E.F.F.; MONTENEGRO, S.M.G.L. 2011. Produtividade do repolho utilizando cobertura morta e diferentes intervalos de irrigação com água moderadamente salina. Revista Brasileira de Engenharia Agrícola e Ambiental, Campina Grande, v. 15, n. 3, p. 256-263.

CUMMING, G.; FIDLER, F.; VAUX, D.L. 2007.Error bars in experimental biology. The Journal of Cell Biology, New York, v.177, n. 1, p.7-11.

CUNHA, G.A.P. 2007. Equipe técnica do abacaxi comemora 30 anos de atividades e realizações. Cruz das Almas: Embrapa Mandioca e Fruticultura Tropical. 19 p.
(Documentos, 170). Disponível em: $<$ http://www.cnpmf.embrapa.br/publicac oes/documentos/documentos_170.pdf> Acesso em: 03 Jan. 2014.

EMBRAPA. 2006. Empresa Brasileira de Pesquisa Agropecuária. Sistema brasileiro de classificação de solos. 2 . Ed. Brasília: Embrapa. 306p.

FAO. 2014. Food and Agriculture Organization of the United Nations. Disponível em: <http://www.fao.org> Acesso em: 03 de Jan. 2014.

IBGE. 2014. Instituto Brasileiro de Geografia e Estatística. Disponível em: www.ibge.gov.br. Acesso em: $14 \mathrm{Fev}$. 2014.

LIMA, M.E.; CARVALHO, D.F.; SOUZA, A.P.; GUERRA, J.G.M.; RIBEIRO, R.L.D. 2009. Desempenho da alface em cultivo orgânico com e sem cobertura morta e diferentes lâminas d'água. Ciência e Agrotecnologia, Lavras, v.33, n. 6. p.1503-1510.

NEVES, S.M.S.; NUNES, M.C.M.; NEVES, R.J. 2011. Caracterização das condições climáticas de Cáceres/MT Brasil, no período de 1971 a 2009: subsídio às atividades agropecuárias e turísticas municipais. Boletim Goiano de Geografia, Goiânia, v. 31, n. 2, p. 55-68. OLIVEIRA, F.F.; GUERRA, J.G.M.; ALMEIDA, D.L.; RIBEIRO, R.L.D.; ESPINDOLA, J.A.A.; RICCI, M.S.F.; CEDDIA, M.B. 2008. Avaliação de coberturas mortas em cultura de alface sob manejo orgânico. Horticultura Brasileira, Brasília, v. 26, n. 2, p. 216220.

PY, C.; LACOEUILHE, J.J.; TEISON, C. 1984. L'ananas, sa culture, ses produits. Paris: G.P. Maisonneuve \& Larose. 562p.

RAIJ, B.V. 2008. Gesso na agricultura. Campinas, Instituto Agronômico. 233 p. 
RIBEIRO, A.C.; GUIMARÃES, P.T.G.;

ALVAREZ, $\quad$ V.H. 1999.

Recomendações para o uso de corretivos e fertilizantes em Minas

Gerais - $5^{\mathrm{a}}$ Aproximação. Viçosa: CFSEMG, $359 \mathrm{p}$.

RDCT. R. 2009. Development Core Team.

$R$ : a language and environment Statistical computing. Vienna: R Foundation for Statistical

Computing.409 p.

REINHARDT, D.H.R.C.; CABRAL, J.R.S.;

SOUZA, L.F.S. 2000.Abacaxi.

Produção: aspectos técnicos. Brasília: Embrapa Mandioca e Fruticultura. 77 p. (Frutas do Brasil, 7).

RODRIGUÊS, A.A.; MENDONÇA, R.M. N., SILVA, A.P.; SILVA, S.M.; PEREIRA, W.E. 2010. Desenvolvimento vegetativo de abacaxizeiros 'Pérola' e 'Smooth Cayenne' no Estado da Paraíba. Revista Brasileira de Fruticultura, Jaboticabal, vol. 32, n. 1, p. 126-134.

SANTOS, C.A. ZANDONÁ, S.R.; ESPINDOLA, J.A.A.; GUERRA, J.G. M.; RIBEIRO, R.L. D. 2011. Efeito de coberturas mortas vegetais sobre $\mathrm{o}$ desempenho da cenoura em cultivo orgânico. Horticultura Brasileira, Brasília, v.29, n. 1, p. 103-107.

SEDIYAMA， M.A.N.; SANTOS， M.R.; VIDIGAL, S.M.; SANTOS, I.C.; SALGADO, L.T. 2010. Ocorrência de plantas daninhas no cultivo de beterraba com cobertura morta e adubação orgânica. Planta Daninha, Viçosa, v. 28, n. 4, p. 717-725.

VITTI, G.C.; LUZ, P.H. C.; MALAVOLTA, E.; DIAS, A.S.; SERRANO, C.G. E. 2008. Uso do gesso em sistemas de produção agrícola. Piracicaba: GAPE. $104 \mathrm{p}$. 